\title{
Hipótesis y metodología en torno a la atribución de autorías en la Colección Castellano de la BNE
}

\author{
Stéphany ONFRAY \\ Universidad Complutense de Madrid \\ Departamento de Historia del Arte III \\ Stephany-o@live.fr
}

Recibido: 26-01-2015

Aceptado: 30-09 2015

\section{RESUMEN}

Este artículo pretende analizar las diferentes teorías emitidas en torno a las autorías de la Colección Castellano, conservada en la Biblioteca Nacional de España. De este modo podremos estar en posición de confirmarlas o matizarlas, gracias al empleo de nuevas metodologías comparativas de los suelos y decorados de los estudios fotográficos en el Madrid decimonónico.

Palabras clave: Historia de la fotografía. Siglo XIX. Madrid. Manuel Castellano. Biblioteca Nacional de España. Colección Castellano. Metodología comparativa.

\section{Hypothesis and Methodology on the Autorship of the Castellano's Collection Photographs}

\begin{abstract}
This article analyzes the different theories issued around the authorship of the Castellano's Collection, preserved in the National Library of Spain. Thus, we will be in a position to confirm or clarify them, through the use of new comparative methodologies of grounds and decorative objects used in a nineteenth-century's studio in Madrid.
\end{abstract}

Key Words: History of Photography. Nineteen Century. Madrid. Manuel Castellano. National Library of Spain. Castellano's Collection. Comparative Method.

Sumario: 1. Introducción. 2. La Colección Castellano y sus Retratos. 3. Verificación y ampliación de estas hipótesis y metodología de atribución: el caso del decorado y de los suelos. 4. Conclusiones. 


\section{Introducción}

El acercarse a la Colección Castellano plantea de antemano dos dificultades que le han ayudado a mantenerse en un espacio poco frecuentado dentro de la historia de la fotografía española del siglo XIX. Su amplitud -está compuesta de más de 18.000 fotografías - y el añadido de que no se haya encontrado hasta hoy una documentación sólida para apoyar teorías en cuanto a orígenes o autores, hacen de este fondo un tema de estudio complejo y un tanto desamparado. No obstante, estos obstáculos pueden parangonarse a su interés, no sólo para la historia del desarrollo de la fotografía en España sino también, si nos centramos en los 17.000 retratos de personalidades y anónimos que reagrupa, para el estudio de los círculos sociales madrileños en el siglo XIX. La recurrente falta de información acerca de los retratos fotográficos del novecientos permitió el desarrollo de nuevas vías de investigación basadas en metodologías formalistas e iconografías que ayudaron a ampliar el conocimiento entorno a la historia de estos materiales.

\section{La Colección Castellano y sus retratos}

Los veintidós álbumes de retratos que componen la Colección Castellano se encuentran actualmente conservados en la Sección de Bellas Artes y Cartografía de la Biblioteca Nacional ${ }^{1}$ de España, con el resto de su amplio fondo fotográfico formado por más de dos millones de piezas ${ }^{2}$, relacionadas tanto con el siglo XIX como con el XX. Gracias al constante trabajo de la institución y a pesar de la evidente delicadeza del material ${ }^{3}$, varios álbumes o fotografías sueltas participaron en algunas exposiciones, principalmente en la propia Biblioteca Nacional, de las que destacan La fotografía en España hasta 1900 en 1982, 150 años de fotografia en la Biblioteca Nacional" en 1989 y, también, la más reciente Fotografía en España. 1850-1870 en 2014. Sin embargo, la Colección Castellano todavía consta de muchos aspectos por descubrir y difundir para que adquiera el valor que realmente se merece. Aunque el presente estudio se centre en torno a los retratos de la colección y en el desarrollo de una metodología para su estudio, conviene mencionar la segunda parte de la colección, que reagrupa unas 700 vistas de ciudades, tanto españolas como extranjeras, y que también necesitaría que le consagren una atención particular. Además, aparte de estos conjuntos, existen entre 250 o 300 fotografias sueltas que, a pesar de la gran

1 Aprovechamos para agradecer la jefa del departamento de estampas y grabados de la sala de Bellas Artes, Isabel Ortega, para su constante atención y ayuda.

2 SÁNCHEZ VIGIL, Juan Miguel, El documento fotográfico. Historia, usos, aplicaciones, Trea, Gijón, 2006, p.248.

3 ORTEGA, Isabel, "Los fondos fotográficos de la Biblioteca Nacional. Su naturaleza y estructura" en A Distancia, UNED, núm.1, Enero de 1991, p.82. "Debido a la gran delicadeza del material fotográfico que conforma esta colección [1a Colección Castellano] es desaconsejable su manipulación, por lo que el acceso a los originales ha de ser restringido." 
probabilidad de pertenecer a la colección, no han sido adjuntadas a ella por cuestiones de organización y conservación ${ }^{4}$.

Según la Biblioteca Nacional, y en particular gracias al trabajo de Isabel Ortega García y Gerardo Kurtz reflejado en su publicación 150 años de fotografía en la Biblioteca Nacional, sabemos que los originales estarían fechados aproximadamente entre 1850 y $1875^{5}$, en plena edad de oro de la fotografía decimonónica. Es justamente en esta época que el dueño original de esta colección, Manuel Blas Rodríguez Castellano y de la Parra, o Manuel Castellano (1826-1880), denominado por todos como pintor de historia ${ }^{6}$, se dedicó a recopilar las miles de piezas fotográficas que componen el fondo actual. No obstante, frente a la falta de documentación conservada, resulta muy difícil esbozar las intenciones reales del pintor al conservar estos álbumes; lo único que quedaría perfectamente claro sería que Manuel Castellano nunca fue fotógrafo y por tanto no es autor de ninguna de las fotografías. Aún así, el hecho que sea uno de los modelos más recurrentes de la colección muestra una afición real a la fotografía por parte del pintor.

Asimismo, la Colección Castellano representa una joya para el estudio de las técnicas fotográficas del siglo XIX y de su utilización en España ya que reagrupa -aparte del daguerrotipo del que no existe ningún ejemplar- todas las técnicas empleadas en la época, y en particular el papel a la sal y la albúmina en el caso de los retratos. Considerando los veintidós álbumes, vemos que estuvieron organizados de forma aleatoria siguiendo, parece ser, el criterio del formato para su agrupamiento:

"Cinco álbumes de formato grande $(440 \times 320 \mathrm{~mm})$ que contiene en total 783 fotografias de formato mayor [tomo 18 a 22]. Diecisiete álbumes pequeños (230x310mm) que contiene un total de 16.043 fotografías de diversos tamaños [tomo 1 a 17]."7

La escasez de la documentación conservada acerca de los orígenes de la Colección Castellano no permite elaborar un estudio completo de sus condiciones de formación. Aún así, algunos historiadores se han arriesgado a emitir ciertas hipótesis en torno al fondo de la Biblioteca Nacional, y en particular sobre la cuestión de las autorías que todavía resulta ser una de las grandes preguntas relativas a la colección. Para ello, se concentraron en la búsqueda de los propietarios de estudios fotográficos, activos en el Madrid de la mitad del siglo XIX, apoyándose a la vez en las pocas fotografías firmadas de la colección. En ellas se encuentran imágenes de los principales fotógrafos de la época como José Martínez Sánchez (1808-1874), Eusebio Juliá (1830-1895), Pedro Martínez de Hebert (ca.1840-1895) o Jean Laurent (1819-1886) ${ }^{8}$.

4 KURTZ, Gerardo y ORTEGA, Isabel, 150 años de fotografía en la Biblioteca Nacional. Guía - inventario de los fondos fotográficos, Biblioteca Nacional, El Viso, Madrid, 1989, p.187.

5 idem.

6 BLASCO, Eusebio, "Manuel Castellano", Dia de Moda, 5 de abril de 1880, año I, n9, p. 4. "De día, pintaba. Le daba por los cuadros de historia".

7 KURTZ, Gerardo y ORTEGA, Isabel, op. cit., p.186.

8 PÉREZ GALLARDO, Helena, Fotografía y arquitectura en España, 1839-1886, p.488 [En línea] http://eprints.ucm.es/23135/1/T34814.pdf [Ultima consulta el 2 de septiembre de 2014]. 


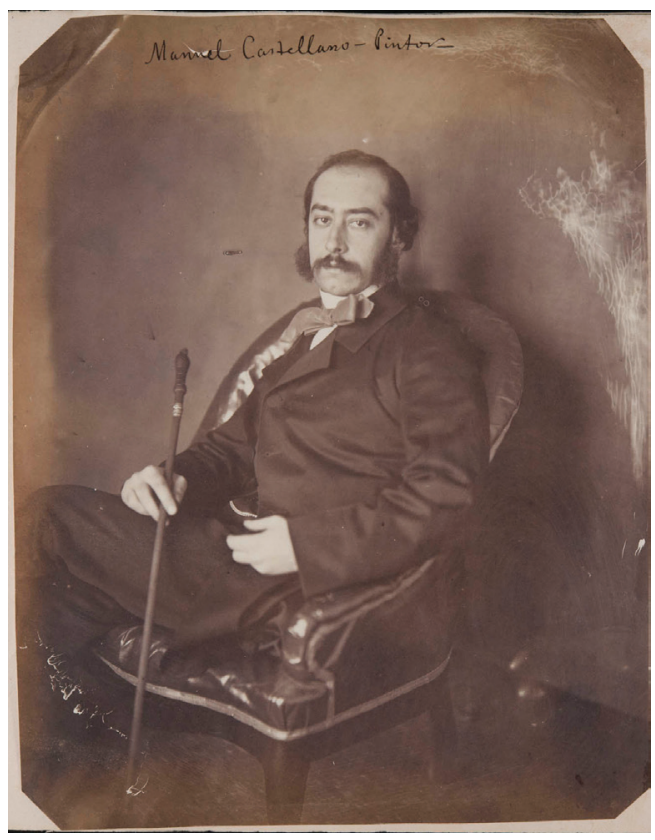

Fig. 1. Retrato de Manuel Castellano, 1856, Biblioteca Nacional, Madrid.

Gerardo Kurtz ha sido el historiador que más allá ha ido en las atribuciones de autorías, aunque para ello restringe particularmente el protagonismo del pintor en la formación de la colección. Según él, los conjuntos de retratos estuvieron compuestos por "los álbumes que tuviera en su gabinete madrileño el fotógrafo José Martínez Sánchez". Aunque puntualiza que la colección todavía no ha sido estudiada lo suficiente para afirmarlo de manera segura, "buena parte del contenido de los álbumes está confeccionado con la producción que se hiciera en el gabinete de este fotógrafo" ". Además, incluye en su teoría varias de las muestras sueltas que, según él, podrían asimilarse a algunas obras del fotógrafo que no estén incluidas en dicha compilación. Sin embargo, es importante recordar que la colección no solamente consta de fotografías de José Martínez Sánchez, sino de muchas otras firmadas por otros autores. Ante esta duda, Kurtz explica que, en el siglo XIX, las relaciones interprofesionales entre artistas eran muy comunes y que la fotografía no estaba exenta de ello. Imaginamos que se refería a la existencia de reuniones entre fotógrafos en las que podrían hablar de su oficio, intercambiando sus nuevas fotografías ${ }^{11}$ o al surgimiento, a partir de los años 1860, de numerosos artículos dedicados al nuevo medio en los boletines oficiales de las sociedades fotográficas y las revistas científicas de

9 SÁNCHEZ VIGIL, Juan Miguel (coord.), Summa Artis XLVII. La fotografía en España, de los orígenes al siglo XXI, Espasa Calpe, Madrid, 2001, p.152.

10 SÁNCHEZ VIGIL, Juan Miguel (coord.), op. cit., pp.152-153.

11 SÁNCHEZ VIGIL, Juan Miguel (coord.), íbidem., p.153. 


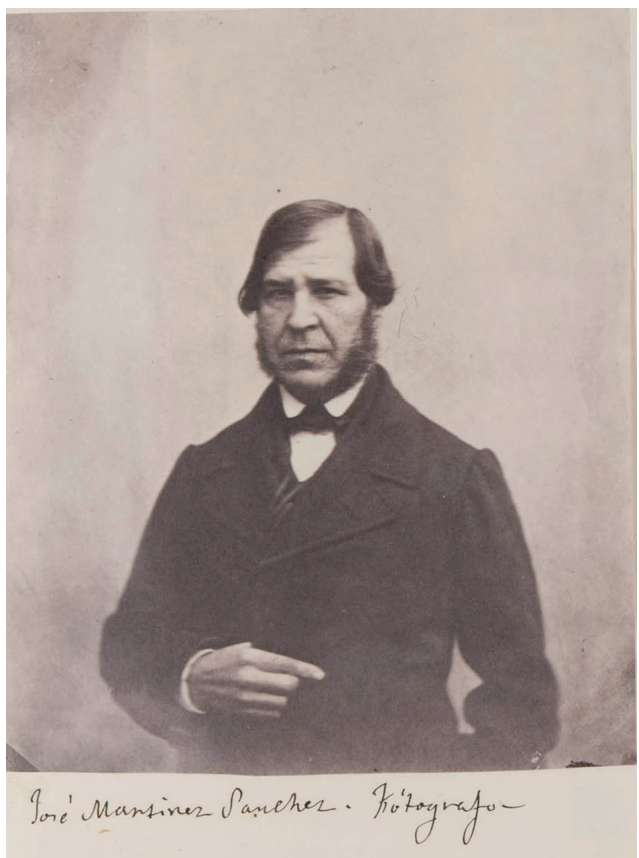

Fig. 2. Retrato de José Martínez Sánchez, Fotógrafo, 1855, Biblioteca Nacional, Madrid.

la época ${ }^{12}$. Hasta conocemos intercambios entre fotógrafos españoles y sus homólogos franceses: pensamos en particular a la colaboración entre el Conde de Vernay y Disderi ${ }^{13}$, o a los numerosos viajes profesionales de Eusebio Juliá y José Martínez Sánchez a Paris ${ }^{14}$. La cuestión del "¿Cómo Manuel Castellano hubiera podido tener acceso a esta cantidad de imágenes?” tampoco resulta problemática para Gerardo Kurtz ya que explica que la mayoría de los fotógrafos instalaban en sus estudios una sala "de espera" 15 , para que su clientela pudiera disfrutar apaciblemente de los álbumes dejados inocentemente en la mesilla antes de su turno. Semejante práctica les permitía presumir de la calidad de su trabajo, pero también ayudaba a sus clientes a cumplir el sentirse orgullosos de entrar en un salón dónde tanta "gente de bien" ya había pasado ${ }^{16}$, apoyando así la idea de "estimulante social" que se hacían entonces de la fotografía. Resulta muy fácil deducir que esta práctica también pudo ser una de las causas del aspecto repetitivo que podían tener estas fotografías, impulsando el uso sistemático de unos tipos de retratos con accesorios específicos, parecidos a los que

12 PÉREZ GALLARDO, Helena, op. cit., p.307.

13 PÉREZ GALLARDO, Helena, íbidem., p.509

14 PÉREZ GALLARDO, Helena, íbidem., p.319.

15 Para tener una mejor imagen de los estudio fotográficos madrileños en el siglo XIX, véase el artículo "Progresos de Fotografía en España", La Esperanza, 12 de octubre de 1858, sobre el estudio de Alonso Martínez, publicado en PÉREZ GALLARDO, Helena, op. cit., pp.318-322.

16 idem. 
los clientes podían observar en estos "catálogos". Para Gerardo Kurtz, es justamente este tipo de álbumes el que podría haber recuperado Manuel Castellano, ya que tenía buenas relaciones con el fotógrafo; pero se puede añadir que era frecuente la venta de álbumes completos por parte de algunos fotógrafos como, por ejemplo, ocurrió con las numerosas publicaciones de Jean Laurent o los Almanaques de Eusebio Juliá. No se puede, por lo tanto, excluir la posibilidad de una compra por parte del pintor, aunque no tengamos ningún documento atestiguándolo.

Si bien la teoría de la adquisición posterior de los álbumes por Castellano sea bastante razonable, persisten varias zonas oscuras en torno a su papel en la formación de la colección. Resulta muy atrevido olvidarse del afán coleccionista del pintor, ya que gran parte de estos libros estaban compuestos por numerosos retratos de amigos suyos. ${ }^{17} \mathrm{Y}$ sobre todo, la hipótesis de la adquisición de álbumes pre-montados solamente podría aplicarse a los retratos de la colección y no al resto del conjunto que reunió Manuel Castellano. Así, a pesar de los muchos elementos que confirmarían la hipótesis de Gerardo Kurtz, para un mejor conocimiento del fondo es primordial matizarlo mediante diversas metodologías.

\section{Verificación y ampliación de estas hipótesis y metodología de atribución: el caso del decorado y de los suelos}

Es importante considerar que el análisis técnico de algunos retratos sería conveniente a la hora de corroborar la hipótesis de Gerardo Kurtz. La sola utilización de papel leptográfico en varios retratos del propio fotógrafo y en los de su mujer Alejandra Alba, fechados hacia 1866, resulta muy significativa ya que lo había patentado justamente en asociación con Jean Laurent ese mismo año ${ }^{18}$. No obstante sería muy tajante atribuir todas las fotografías de papel leptográfico a José Martínez Sánchez y tampoco podemos dejar aparte las otras técnicas empleadas en el conjunto de retratos. De hecho, resulta bastante improbable que el fotógrafo se haya limitado al solo uso de este papel.

Si nos centramos el aspecto formal de los álbumes, resalta ampliamente el parecido entre las imágenes de una misma página de álbum. Muchas de las fotografías podrían entonces proceder de un mismo estudio como afirma Gerardo Kurtz, ya que en varias de ellas se repiten tanto los retratados como los decorados, accesorios o suelos. Al considerar la importancia de este tipo de detalles decorativos para la verificación de las hipótesis y la determinación de las autorías de la colección, se ha querido desarrollar y ampliar el método utilizado por Pablo Linés Viñuales en otra

17 Podemos afirmar que muchos de los retratados fueron conocidos por Castellano, no sólo porque muchas de las fotografías corresponden con las cartas, sino porque detrás de numerosas piezas el pintor apuntó el nombre de los retratados incluso algún escueto comentario. Como ya se ha dicho, los álbumes siendo muy frágiles resultaría muy dañino el despegar las fotografías para tener acceso a sus reversos. La ayuda de Isabel Ortega ha resultado entonces imprescindible tanto a la hora de obtener la transcripción de algunos de estos apuntes, como para definir las dimensiones, técnicas y datación de algunas de las fotografías.

18 PÉREZ GALLARDO, Helena, op.cit., p.487. La doctora Pérez Gallardo trata más en profundidad sobre la presentación de este papel a la Sociedad francesa de fotografía. 
colección fotográfica madrileña: la colección Pedro Antonio de Alarcón de la Fundación Lázaro Galdiano ${ }^{19}$. El investigador aplicó a la colección un sistema elaborado a partir de los decorados y particularmente los suelos presentes en las imágenes, pues la correspondencia de dichos suelos con otros de fotografías firmadas de la época permite la atribución de los retratos. Es evidente que los decorados de los estudios eran movibles y que se adaptaban en función de las voluntades de los clientes. Sin embargo, por lo difícil que resultaba cambiar las moquetas, los mismos suelos aparecían más a menudo en los retratos; se transformaron entonces en aliados valiosos a la hora de determinar en qué estudio se sacaron las pruebas. Pudimos entonces emplear esta misma metodología para la Colección Castellano, extendiéndola además a los varios objetos presentes en los "escenarios fotográficos", como los manteles, las columnas o los objetos decorativos. De esta manera, independientemente de que se vea el suelo en los retratos, pudimos relacionar estos objetos con fotografías en las que sí aparecían tanto el objeto como el suelo, o también nos permitió la identificación de nuevos suelos para los estudios que ya conocíamos. Uno de los mejores ejemplos para ilustrarlo sería la tercera página del tomo 14 de la Colección Castellano ${ }^{20}$.

Si nos centramos en la muestra del álbum podemos constatar que al conocer la correspondencia del suelo de la tercera imagen con una fotografía firmada por José Martínez Sánchez, conviene ampliar la reflexión e imaginar que el vaso de flores y la columna de madera, presentes en la misma imagen, también pertenecen al estudio del fotógrafo. Así, podemos extrapolarlo a la primera fotografía en la que encontramos la misma columna de madera y, de esta manera, atribuir una nueva escultura femenina así como un nuevo suelo a este estudio. Vemos entonces que esta página podría estar atribuida en su globalidad a José Martínez Sánchez si utilizamos este método. Aunque no se pueda considerar este procedimiento como infalible, la frecuente correspondencia de las deducciones sacadas con la relación entre modelo y fotógrafo nos han permitido confirmarlo las suficientes veces como para que sea muy seriamente tenido en cuenta $^{21}$. Como se puede constatar este proceso nos permitió, en particular, confirmar la importancia de José Martínez Sánchez para la colección ya que es el autor de la mayor parte de los retratos. Del mismo modo, podemos asegurar que, en un gran número de fotografías de la colección, los suelos corresponden con los de fotografías firmadas por Eusebio Juliá. Por último, existen algunos casos en los que encontramos suelos correspondientes a estudios nunca citados como participantes de la colección, como sería el caso del fotógrafo Juan Rodríguez (activo hacía 1860) ${ }^{22}$, lo que permite abrir nuevas puertas, primordiales para el estudio de la colección y de sus autores.

19 Véase LINÉS, VIÑUALES, Pablo, "Posar en un escenario: la imagen en la carte de visite", en Una Imagen para la Memoria. La carte de visite. Colección de Pedro Antonio de Alarcón [cat. exp.], Fundación Lázaro Galdiano, Madrid, 2011, pp.134-135.

20 Ver por ejemplo el tomo 14 de las Fotografias recogidas por el pintor Manuel Castellano, tomo 14, 17-LF/59, Biblioteca Nacional, Madrid. [En línea] http://bdh-rd.bne.es/viewer.vm?id=0000144325\&page=1 [Última consulta el 10 de septiembre de 2014].

21 Es por ejemplo el caso de muchas de las fotografías de mujeres de fotógrafos cuyos suelos corresponden, al utilizar el método, con los establecimientos de sus esposos.

22 VV.AA., Una Imagen para la Memoria. La carte de visite. Colección de Pedro Antonio de Alarcón [cat. exp.], Fundación Lázaro Galdiano, Madrid, 2011, p.188. 


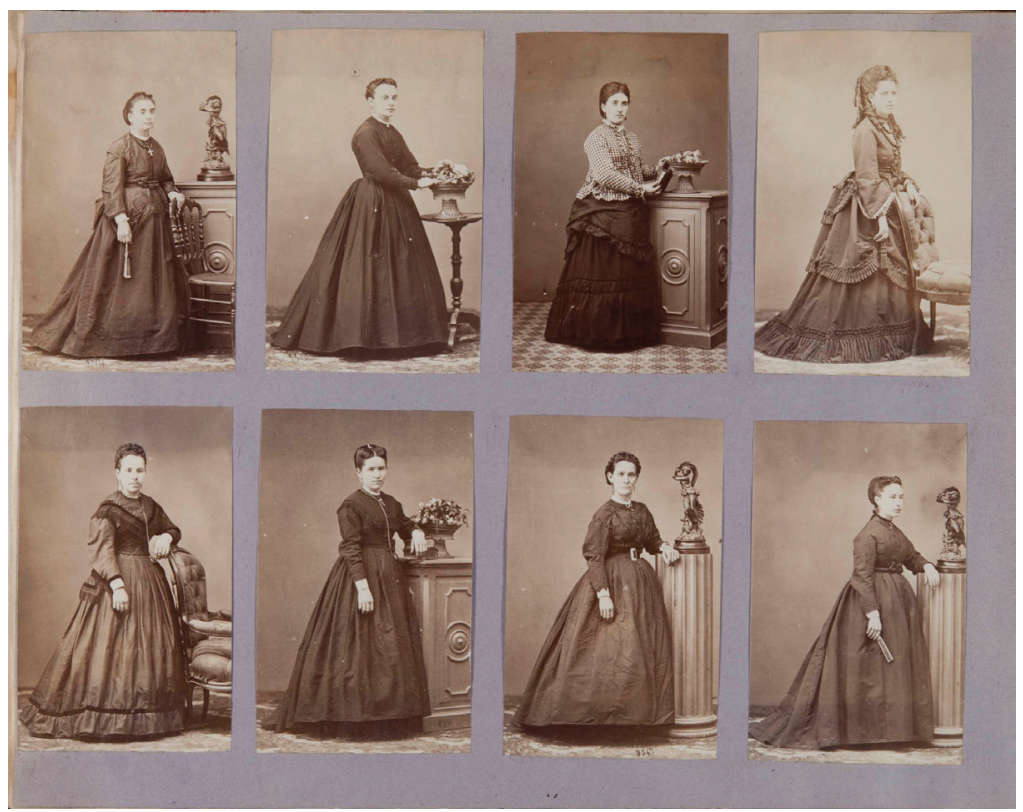

Fig. 3. Muestra de una de las páginas del tomo 14 de la Colección Castellano, Biblioteca Nacional, Madrid.

Otro elemento totalmente abandonado y que consideramos como fundamental para el estudio de la colección sería la correspondencia recogida por Manuel Castellano, igualmente conservada en la Biblioteca Nacional. La consideración de estos centenares de cartas es un camino muy valioso para apoyar estas teorías ya que afirma tanto la relación entre el pintor y José Martínez Sánchez como con Eusebio Juliá. Pensamos en particular en una carta en la que el primer fotógrafo invita al pintor para hablar de la reproducción de un dibujo de toros que le ha pedido uno de sus clientes $^{23}$. En el caso de Eusebio Juliá, que lo podemos relacionar con Manuel Castellano solo indirectamente. A través de una carta escrita desde Barcelona por Juan Catalina (1830-1870), hermano de uno de los mejores amigos de Castellano, el actor Manuel Catalina (1820-1886), podemos comprobar:

"Y a propósito de su venida suplicaré a usted, si no abuso de su amabilidad, que pida à Juliá tres retratos, unos grandes y alguna tarjetas más de las últimas, que me los traiga. " 24

23 Carta de José Martínez Sánchez a Manuel Castellano, 8 de julio s.a., MSS/12946/35, Biblioteca Nacional, Madrid. Véase el apéndice IV. "Amigo Castellanos (sic). Necesitaría ver a usted para hablar de unos dibujos de toros que quiere un sugeto (sic) para reproducirlos en fotografía". Además de una relación de amistad, esta carta podría acreditar unos vínculos profesionales entre los dos hombres.

24 Carta de Juan Catalina a Manuel Castellano, 8 de mayo de 1861, MSS/12946/85, Biblioteca Nacional, Madrid. 


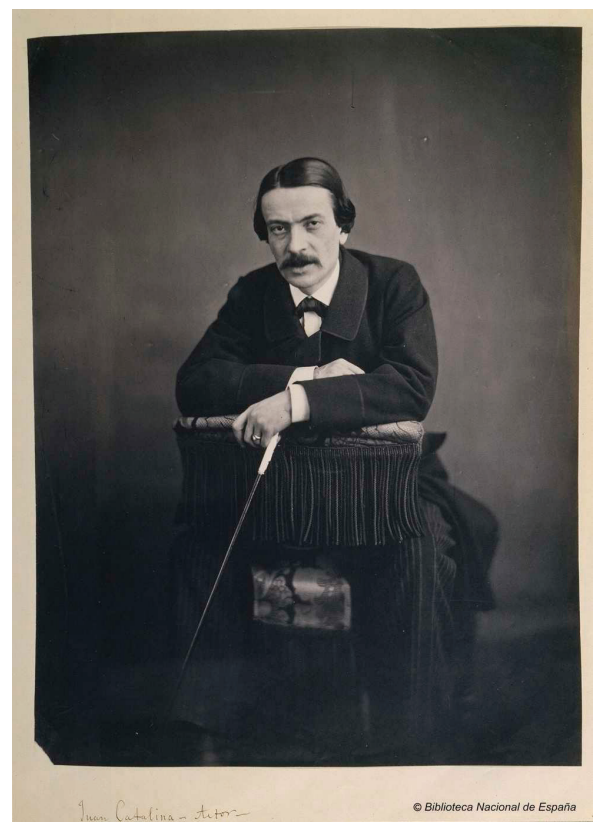

Fig. 4. Retrato de Juan Catalina, 1860, Biblioteca Nacional de Madrid.

Es interesante observar que existen tres retratos de Juan Catalina en la Colección Castellano; uno de ellos es un formato grande ${ }^{25}$, el otro de formato medio ${ }^{26}$ y el tercero es formato tarjeta de visita ${ }^{27}$, justamente como se especifica en la carta. Podemos suponer que Manuel Castellano habrá respondido a la petición de su amigo y que, de paso, habrá ampliado su colección con tres copias de las pruebas. Igualmente, se pueden apreciar relaciones con Eusebio Juliá al consultar el Almanaque de Juliá para el año 1873 en el que está publicado uno de los sonetos del pintor ${ }^{28}$. Es también cierto que no aparece en la lista de artistas retratados por Juliá, publicada al reverso de los Almanaques de 1873 o $1874^{29}$, pero figuran en ella muchos otros pintores, es-

\footnotetext{
25 Fotografias recogidas por el pintor Manuel Castellano, tomo 18, 17-LF/41-037, Biblioteca Nacional, Madrid.

26 Fotografías recogidas por el pintor Manuel Castellano, tomo 11, 17-LF/56-119.7, Biblioteca Nacional, Madrid.

27 Fotografias recogidas por el pintor Manuel Castellano, tomo 2, 17-LF/47-009.6, Biblioteca Nacional, Madrid.

28 JULIÁ, Eusebio, Almanaque para el año 1873, Imp. de R. Labajos, Madrid, 1873, p.65. Es importante subrayar que los talentos poéticos de Manuel Castellano no eran conocidos y que mandaba sus "sonetos" únicamente a algunos amigos suyos. En una carta de 1853 de Francisco Reigón (pintor), conservada en la Biblioteca Nacional MSS/12944/126, vemos como alaba las poesías que le había mandado su amigo Castellano: "Recibí la tuya con el mayor entusiasmo leyendo tus brillantes poesías con admiración extraordinaria y me proporcionaste un rato verdaderamente feliz “. La publicación de alguno de estas poesías en el Almanaque traduce una cierta confianza entre Eusebio Juliá y Manuel Castellano.

29 JULIÁ, Eusebio, Almanaque para el año 1874, Imp. de R. Labajos, Madrid, 1874.
} 


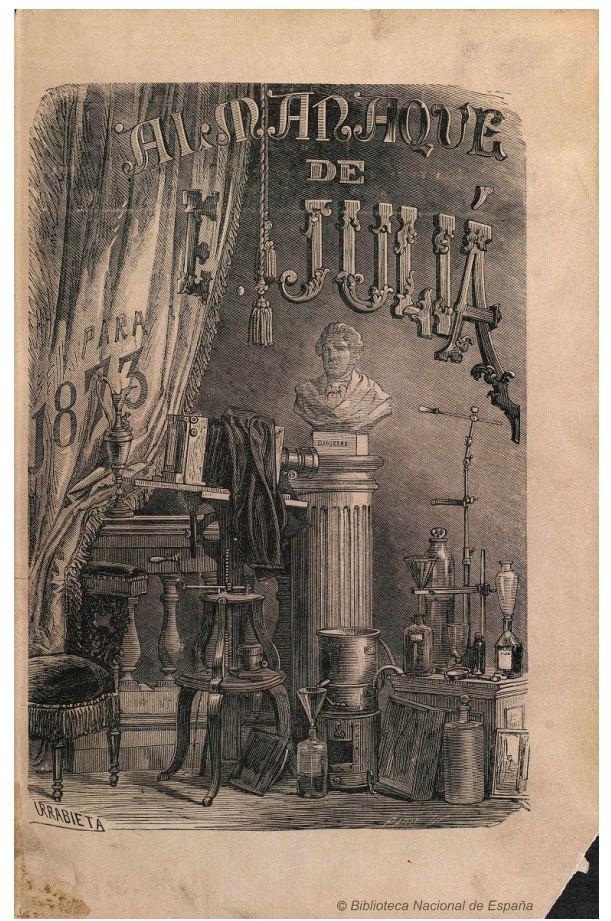

Fig. 5. Portada del Almanaque de Eusebio Juliá para el año 1873, Biblioteca Nacional, Madrid.

critores o actores cuyos retratos se encuentran en la Colección Castellano. Además, la simultánea formación en la Academia de San Fernando de los dos hombres apunta hacia esta dirección ${ }^{30}$. La posibilidad de consultar algún Almanaque anterior permitiría seguramente certificar la afirmación según la cual Castellano y Juliá no sólo se conocían ${ }^{31}$ sino que el fotógrafo había retratado al pintor. Por fin, la propia situación del estudio de Juliá, en la calle del Príncipe apoya esta idea: en ella se encontraba justamente el Teatro del Príncipe, actual Teatro Real, dónde Manuel Castellano se encargaba, en cierta medida, de la venta de entradas ${ }^{32}$.

Aunque José Martínez Sánchez y Eusebio Juliá quedan resaltados como los dos mayores autores de la Colección Castellano, no se excluye por lo tanto la participación de otros en la recopilación. La observación de las propias fotografías ofrece la

30 RUIZ AGUILERA, Ventura, "Sr. D. Eusebio Juliá” en Almanaque de Eusebio Juliá para el año 1874, Imp. de R. Labajos, Madrid, 1874, p.77. Manuel Castellano se formó con Juan Rivera, un pariente de Eusebio Juliá que también formó al fotógrafo en la Academia de San Fernando.

31 Carta de Eusebio Juliá a Manuel Castellano, 1870, MSS/12940/85, Biblioteca Nacional, Madrid. Véase el apéndice IV. Una carta de Juliá destinada a Castellano asegura que se conocían, y más, que eran amigos: "Querido Manolito".

32 BLASCO (1880), Eusebio, op. cit., p.4. "Castellano era el secretario de aquella sección del público, reunida en el clásico coliseo de la calle del Príncipe. [...] Desde las tres en adelante este pintor-actor, digámoslo vivía en el teatro. Tomaba el café en el despacho de billete porque él necesitaba saber cómo iba la entrada". 
prueba de una relación de amistad entre Manuel Castellano y otro fotógrafo madrileño de la época: José Sánchez (activo entre 1850 y 1870). En una primera fotografía, reconocemos los dos hombres en una fotografía de grupo ${ }^{33}$. Las dos muestras siguientes son retratos individuales de José Sánchez ${ }^{34}$ y Manuel Castellano ${ }^{35}$. En ellas no varían ni el suelo del gabinete, ni los trajes lo que nos deja imaginar una sesión de fotografía conjunta que empezaría o acabaría por un retrato de grupo.

\section{Conclusiones}

En conclusión, es importante entender que la idea a la hora de exponer estos argumentos no es sólo el reforzar las hipótesis emitidas en torno a la Colección Castellano y a sus autores, sino también matizarlas para proporcionar una mayor importancia a otros fotógrafos como Eusebio Juliá, Juan Rodríguez o José Sánchez. Para ello, resulta primordial la consideración de nuevas metodologías basadas tanto en la consulta de la amplia y valiosa colección de fuentes epistolares, recopilada por el propio Manuel Castellano, como en el sistemático análisis técnico y formal de los retratos y en particular a través de los accesorios de los decorados. Un estudio completo del fondo podría no sólo aportarnos más detalles sobre el mismo y la sociedad madrileña de la época sino elaborar un estudio sistemático aplicable a la mayor parte de las colecciones fotográficas de Madrid.

33 Fotografias recogidas por el pintor Manuel Castellano, tomo 14, 17-LF/59-100, Biblioteca Nacional, Madrid.

34 Fotografias recogidas por el pintor Manuel Castellano, tomo 14, 17-LF/59-101, Biblioteca Nacional, Madrid.

35 Fotografias recogidas por el pintor Manuel Castellano, tomo 14, 17-LF/59-102, Biblioteca Nacional, Madrid. 